\title{
Epigenetic regulation of gene expression by Drosophila Myb and E2F2-RBF via the Myb-MuvB/dREAM complex
}

\author{
Hong Wen, ${ }^{1}$ Laura Andrejka, ${ }^{1}$ Jonathan Ashton, ${ }^{1}$ Roger Karess, ${ }^{2}$ and Joseph S. Lipsick ${ }^{1,3}$ \\ ${ }^{1}$ Department of Pathology and Department of Genetics, Stanford University, Stanford, California 94305, USA; ${ }^{2}$ Centre \\ National de la Recherche Scientifique (CNRS), Centre de Génétique Moléculaire, 91198 Gif sur Yvette, France
}

\begin{abstract}
The Drosophila Myb oncoprotein, the E2F2 transcriptional repressor, and the RBF and Mip130/LIN-9 tumor suppressor proteins reside in a conserved Myb-MuvB (MMB)/dREAM complex. We now show that Myb is required in vivo for the expression of Polo kinase and components of the spindle assembly checkpoint (SAC). Surprisingly, the highly conserved DNA-binding domain was not essential for assembly of Myb into $M M B / d R E A M$, for transcriptional regulation in vivo, or for rescue of $M y b$-null mutants to adult viability. E2F2, RBF, and Mip130/LIN-9 acted in opposition to Myb by repressing the expression of Polo and SAC genes in vivo. Remarkably, the absence of both Myb and Mip130, or of both Myb and E2F2, caused variegated expression in which high or low levels of Polo were stably inherited through successive cell divisions in imaginal wing discs. Restoration of Myb resulted in a uniformly high level of Polo expression similar to that seen in wild-type tissue, whereas restoration of Mip130 or E2F2 extinguished Polo expression. Our results demonstrate epigenetic regulation of gene expression by Myb, Mip130/LIN-9, and E2F2-RBF in vivo, and also provide an explanation for the ability of Mip130-null mutants to rescue the lethality of $M y b$-null mutants in vivo.
\end{abstract}

[Keywords: Epigenetic; Myb; retinoblastoma; E2F; oncogene; tumor suppressor]

Supplemental material is available at http://www.genesdev.org.

Received October 16, 2007; revised version accepted December 19, 2007.

A central question in developmental biology is the mechanism by which genetically identical cells stably maintain different phenotypic states during successive rounds of mitotic division. Conversely, the disruption of such epigenetic regulation is widely believed to play a key role in cancer (Lund and van Lohuizen 2004). A powerful model for understanding the mechanisms of epigenetic control was provided by Muller's eversporting displacements in Drosophila, which display variegated expression of eye pigment due to the spread of constitutive heterochromatin into adjacent regions of the genome (Muller 1930; Schulze and Wallrath 2007). Parallel systems of epigenetic regulation by Trithorax and Polycomb group proteins were discovered via genetic studies of the Drosophila body plan (Lewis 1978; Schuettengruber et al. 2007).

The retinoblastoma (RB) family of tumor suppressor proteins regulates gene expression by binding to E2F-DP heterodimers, which themselves bind directly to DNA (Classon and Harlow 2002). RB family proteins have been proposed to inhibit gene expression by direct inter-

${ }^{3}$ Corresponding author.

E-MAIL lipsick@stanford.edu; FAX (650) 725-6902.

Article is online at http://www.genesdev.org/cgi/doi/10.1101/gad.1626308. action with components of the classical position effect variegation (PEV) system and/or the Polycomb system (Nielsen et al. 2001; Vandel et al. 2001; Gonzalo et al. 2005; Kotake et al. 2007). However, evidence for epigenetic regulation of gene expression by RB family proteins in vivo has thus far been lacking.

$\mathrm{RB}$ is encoded by the retinoblastoma susceptibility gene $(R B 1)$, loss of which causes both inherited and sporadic retinoblastoma in humans (Classon and Harlow 2002). Two RB-related proteins, p107 and p130, are encoded by the RBL1 and RBL2 genes in vertebrates. These three "pocket" proteins can repress gene expression via the E2F transcription factors. This repression is relieved by phosphorylation of RB-related proteins by the Cyclin D-CDK4 protein kinase, which itself is inhibited by the p16 and p15 CDK inhibitor proteins. The importance of this regulatory circuit is underscored by its mutation in the majority of human cancers.

In vertebrates, the RB-responsive E2F family form heterodimeric DNA-binding proteins composed of one E2F subunit (an E2F1-3 activator or an E2F4-5 repressor) and one DP subunit (DP1 or DP2). Drosophila contains only two RB-related proteins (RBF1 and RBF2), two E2F subunits (an E2F1 activator or an E2F2 repressor), and a single DP subunit. Biochemical studies revealed that the 
Drosophila E2F2, DP, and the RBF proteins are present in a large complex (Myb-MuvB [MMB]/dREAM) that includes the Myb protein, as well as four previously identified Myb-binding proteins (Mip130, Mip120, Mip40, and p55CAF1) (Beall et al. 2002; Korenjak et al. 2004; Lewis et al. 2004). Unexpectedly, loss-of-function mutants of Mip130, M120, or Mip40 can rescue an otherwise lethal $M y b$-null mutant to adult viability (Beall et al. 2004, 2007). With the exception of Myb itself, all of these proteins are conserved in Caenorhabditis elegans and form a similar complex (Lipsick 2004; Harrison et al. 2006). Interestingly, mutation of any one of the corresponding genes (synMuvB) has been shown to cause a synthetic multivulval (synMuv) phenotype in nematodes in combination with mutation of any single gene of another equivalence group (synMuvA or synMuvC) (Ferguson and Horvitz 1989; Ceol et al. 2006). These results imply that synMuv genes act in a redundant fashion to repress the RTK-RAS pathway, activation of which causes a multivulval phenotype. Related MMB/ dREAM-like complexes are also present in human cells (Korenjak et al. 2004; Litovchick et al. 2007; Pilkinton et al. 2007; Schmit et al. 2007).

The $M y b$ gene family was discovered due to the oncogenic transduction of $c-M y b$ by an acutely transforming chicken retrovirus (Lipsick and Wang 1999). All vertebrates examined have three related $M y b$ genes, whereas Drosophila has a single Myb gene (Katzen et al. 1985; Davidson et al. 2004). The highly conserved Myb DNAbinding proteins can regulate gene expression in a variety of experimental systems. Vertebrate A-Myb (MYBL1) and c-Myb $(M Y B)$ are tissue-specific with regard to gene expression and loss-of-function phenotypes in the laboratory mouse (Mucenski et al. 1991; Toscani et al. 1997). In contrast, vertebrate $\mathrm{B}-M y b(M Y B L 2)$ is expressed in all dividing cells, and loss-of-function mutants cause early embryonic lethality (Tanaka et al. 1999).

Drosophila Myb is an essential gene, and loss-of-function mutants cause early prophase arrest, failure of progression of chromosome condensation, aneuploidy, polyploidy, aberrant mitotic spindles, and abnormal centrosome number (Katzen et al. 1998; Fung et al. 2002; Manak et al. 2002, 2007). Similar cell cycle defects occur in B-Myb mutant zebrafish (Shepard et al. 2005). Interestingly, vertebrate $\mathrm{B}-M y b$, but neither $\mathrm{A}-M y b$ nor $\mathrm{c}-M y b$, can complement the cell cycle defects in $M y b$ null Drosophila hemocytes (Davidson et al. 2005). These results imply that $\mathrm{B}-\mathrm{Myb}$ is the vertebrate ortholog of Drosophila Myb. Importantly, increased levels of B-Myb expression correlate with poor prognosis in a variety of human malignancies including breast cancer (Amatschek et al. 2004; Paik et al. 2004).

The RB-E2F axis has primarily been studied as a regulator of the G1/S transition of the cell cycle (Dimova and Dyson 2005). However, Drosophila Myb and vertebrate $\mathrm{B}-\mathrm{Myb}$ mutants disrupt the G2/M transition. Therefore, we sought to understand the mechanism of the mitotic cell cycle defects in $M y b$ mutant cells and to determine the role of $M M B / d R E A M$ in G2/M control. We found that Polo, a regulator of spindle pole assembly and func- tion, is directly regulated by Myb in vivo, as are key components of the spindle assembly checkpoint (SAC). Unexpectedly, we found that Polo displays a variegated pattern of expression in the absence of Myb and Mip130 or of Myb and E2F2. These results demonstrate a role for $\mathrm{MMB} / \mathrm{dREAM}$ in epigenetic regulation of gene expression.

\section{Results}

Loss of Drosophila Myb causes mitotic delay with spindle pole abnormalities

Drosophila Myb-null mutants die as late third instar larvae with aberrant chromosome condensation, ploidy, and mitotic spindle formation in brain and imaginal disc cells (Manak et al. 2002, 2007). To better understand the nature of these mitotic defects, we performed real-time analysis of the cytologically favorable giant larval neuroblasts. We used an RFP-histone $\mathrm{H} 2 \mathrm{avD}$ fusion protein to identify those neuroblasts that had undergone chromosome condensation and a GFP-trap microtubule-associated protein fusion protein to visualize the spindle poles and spindle fibers (Morin et al. 2001; Pandey et al. 2005). We found that $M y b$-null neuroblasts that displayed characteristics of chromosome condensation were dramatically delayed in prometaphase/metaphase with persistently abnormal spindles (Fig. 1A,B; Supplemental Fig. S1). The initially bipolar spindle poles migrated improperly, and the spindle itself was often rotated, bowed, and/or misattached. In addition, the spindle poles in $M y b$-null cells displayed an abnormal and persistent accumulation of GFP-TACC with a larger apparent volume and a much more diffuse, multicentric character than spindle poles in wild-type cells (Supplemental Fig. S1; Barros et al. 2005). Similar spindle abnormalities were observed regardless of the overall length of mitotic delay. These results demonstrate that in addition to the prophase delay with failure of chromosome condensation, $M y b$-null cells that do eventually progress into metaphase experience subsequent abnormalities of the mitotic spindle.

\section{$M y b$ is required for expression of Polo and the SAC}

The spindle pole abnormalities in $M y b$-null larval neuroblasts pointed us toward Polo kinase, a key regulator of spindle pole assembly and function (Glover 2005). We used compartment-specific rescue, which permits the side-by-side analysis of mutant and rescued cells in the same tissue at the same time without direct competition (Manak et al. 2007). We first examined the expression of a GFP-Polo fusion protein under control of the normal Polo transcriptional regulatory elements in larval imaginal wing discs, which increase from 50 to 50,000 cells during the third instar period of development and eventually give rise to adult wings (Fig. 1C, panels a,g; Moutinho-Santos et al. 1999). We found that in the absence of Myb, levels of GFP-Polo were greatly reduced in mitosis and during interphase. 
A

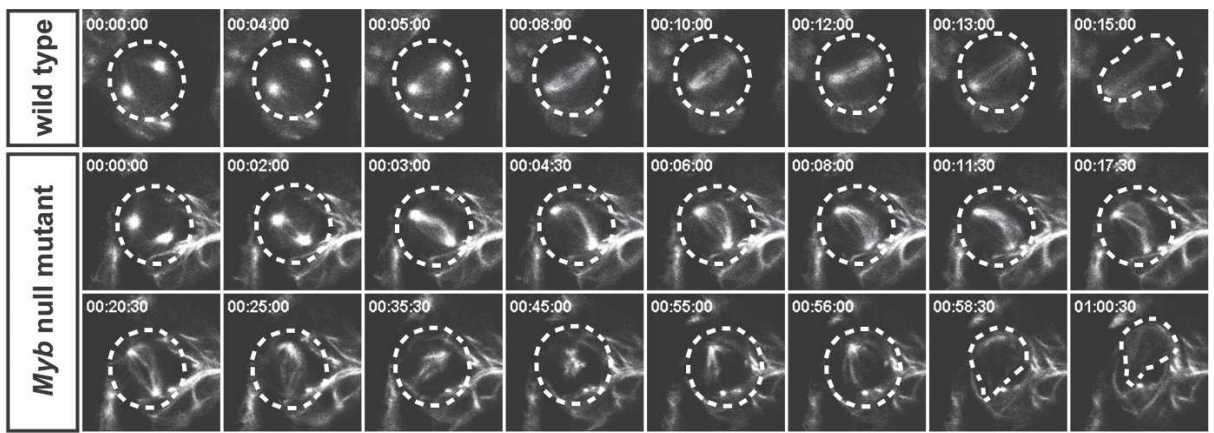

B

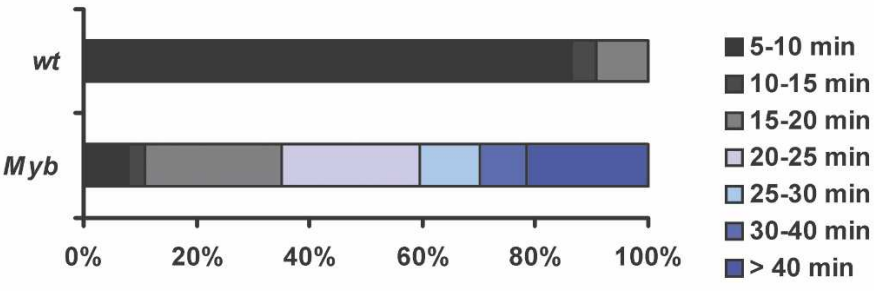

percentage
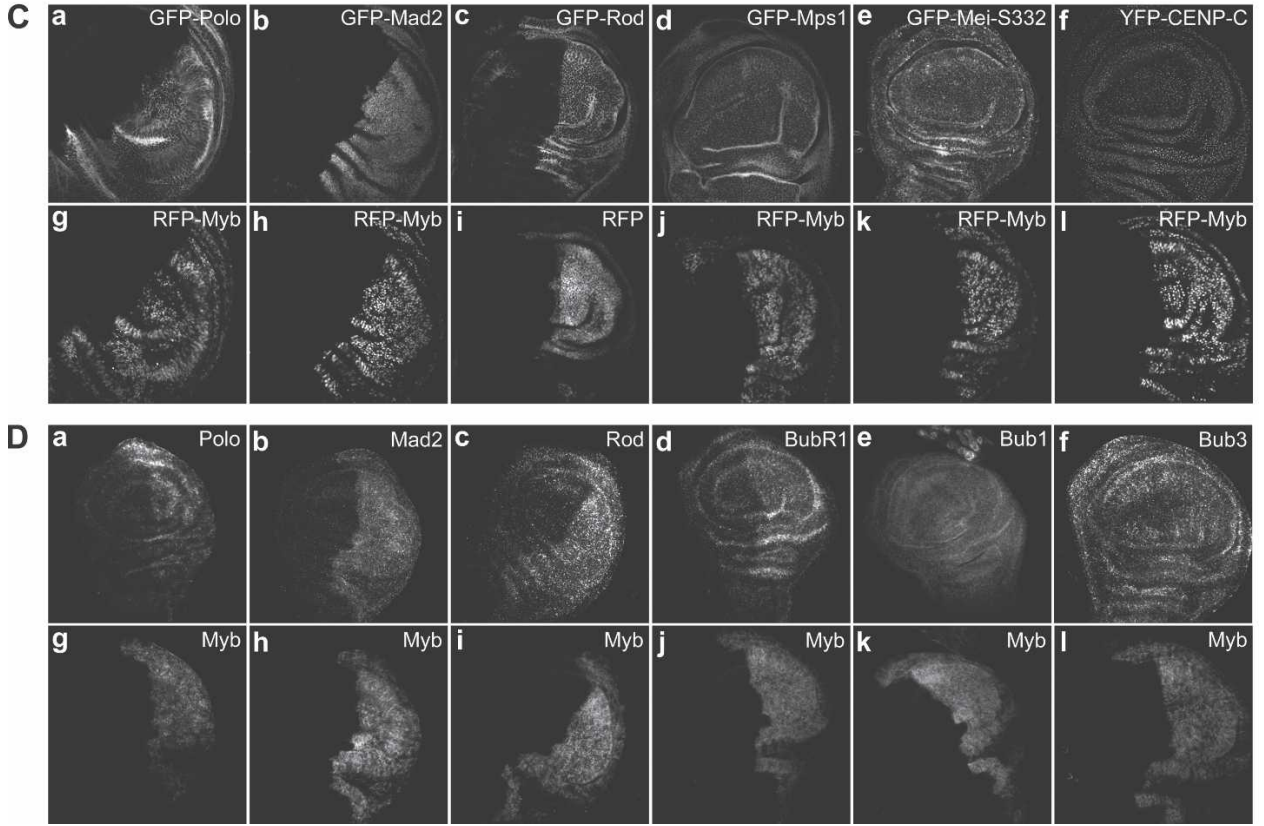

Figure 1. Loss of $M y b$ causes mitotic delay, and $M y b$ is required for expression of Polo and the SAC. (A) Wild-type or $M y b$-null larval neuroblasts expressing GFP microtubule-associated protein (GFP protein trap G147) and RFP-histone H2avD were visualized by time-lapse laser scanning confocal microscopy. Only GFP is shown here. RFP-H2avD is also shown in Supplemental Figure S1. Myb mutant cells entering mitosis spent a much longer time in metaphase and displayed abnormal spindle morphology. The time is in hours:minutes:seconds with $T_{0}$ set at the start of imaging. Broken circles indicate cells in mitosis. $(B)$ Bar graph showing distribution of the duration of larval neuroblast mitosis for wild-type (wt, $N=22)$ and $M y b$-null mutant $(N=37)$. The time in minutes indicates the duration of mitosis from spindle pole apposition to onset of anaphase. $(C, D)$ Imaginal wing discs from $M y b$-null larvae in which RFP-Myb or unfused Myb protein was expressed in the posterior compartment via the GAL4-UAS binary system. ( $C$, panels $a-f)$ Fluoresence of indicated fusion proteins expressed from native promoters. Shown directly below each panel are fluorescence of RFP-Myb (panels $g, h, j-1$ ) or RFP coexpressed with Myb (panel $i$ ) in the same imaginal discs. ( $D$, panels $a-f$ ) RNA in situ hybridizations for expression of endogenous genes as indicated. (Panels $g-1$ ) Shown directly below each panel are RNA in situ hybridizations for $M y b$ in the same imaginal discs. In this and other photomicrographs of wing imaginal discs, anterior is to the left.

Because alterations in ploidy occur in Drosophila $M y b$-null larvae, we also examined components of the SAC (Karess 2005; Musacchio and Salmon 2007). In the absence of Myb, we observed dramatic reductions of GFP-Mad2, a key component of the highly conserved mitotic checkpoint complex (MCC), and of GFP-Rod, a 
key component of the animal-specific RZZ complex (Fig. 1C; Buffin et al. 2005). Similar observations were made for GFP-BubR1, another component of the MCC complex (data not shown). However, several other proteins required for proper chromosome behavior during mitosis were unaffected in the absence of Myb, including Mps1, a SAC kinase; Mei-S332/Shugoshin, a regulator of centromeric sister chromatid cohesion; and CENP-C, a conserved inner kinetochore component (Fig. 1C).

We found that levels of a GFP-Mad2 fusion protein expressed under control of the Ubiquitin promoter were not affected by the presence or absence of Myb (data not shown). This result implied that Myb did not affect GFPMad2 protein stability, but rather affected GFP-Mad2 mRNA levels only when expressed under control of the normal Mad2 transcriptional regulatory elements. To determine if the endogenous Polo and SAC genes were regulated by Myb at the mRNA level, we performed in situ hybridization on imaginal wing discs from $M y b$-null animals in which cells in the posterior, but not the anterior compartments, were rescued by expression of a
Myb cDNA (Fig. 1D). Polo, Mad2, Rod, and BubR1 mRNA levels were highly dependent on the presence of Myb. In contrast, the expression of two other genes encoding SAC components, Bub1 and Bub3, were not affected by the absence of Myb.

Loss of Myb results in a failure of progression of chromosome condensation such that the phosphorylation of Ser 10 on histone H3 occurs normally in heterochromatin but fails to spread to euchromatin (Manak et al. 2007). However, this failure of chromosome condensation occurred only after many cell divisions in the absence of Myb. To determine the kinetics of the loss of Polo and SAC gene expression in the absence of Myb, we performed genetic mosaic analysis using the FLP-FRT system (Golic 1991). Cells containing a wild-type $M y b$ allele were marked by RFP-HP1, whereas Myb-null clones were RFP-negative (Fig. 2). Nuclei were counterstained with TOTO-3, a DNA dye with a preference for heterochromatin. We observed that GFP-Polo and GFPMad2 expression were extinguished in the absence of Myb, even in very small mutant clones (Fig. 2). Control

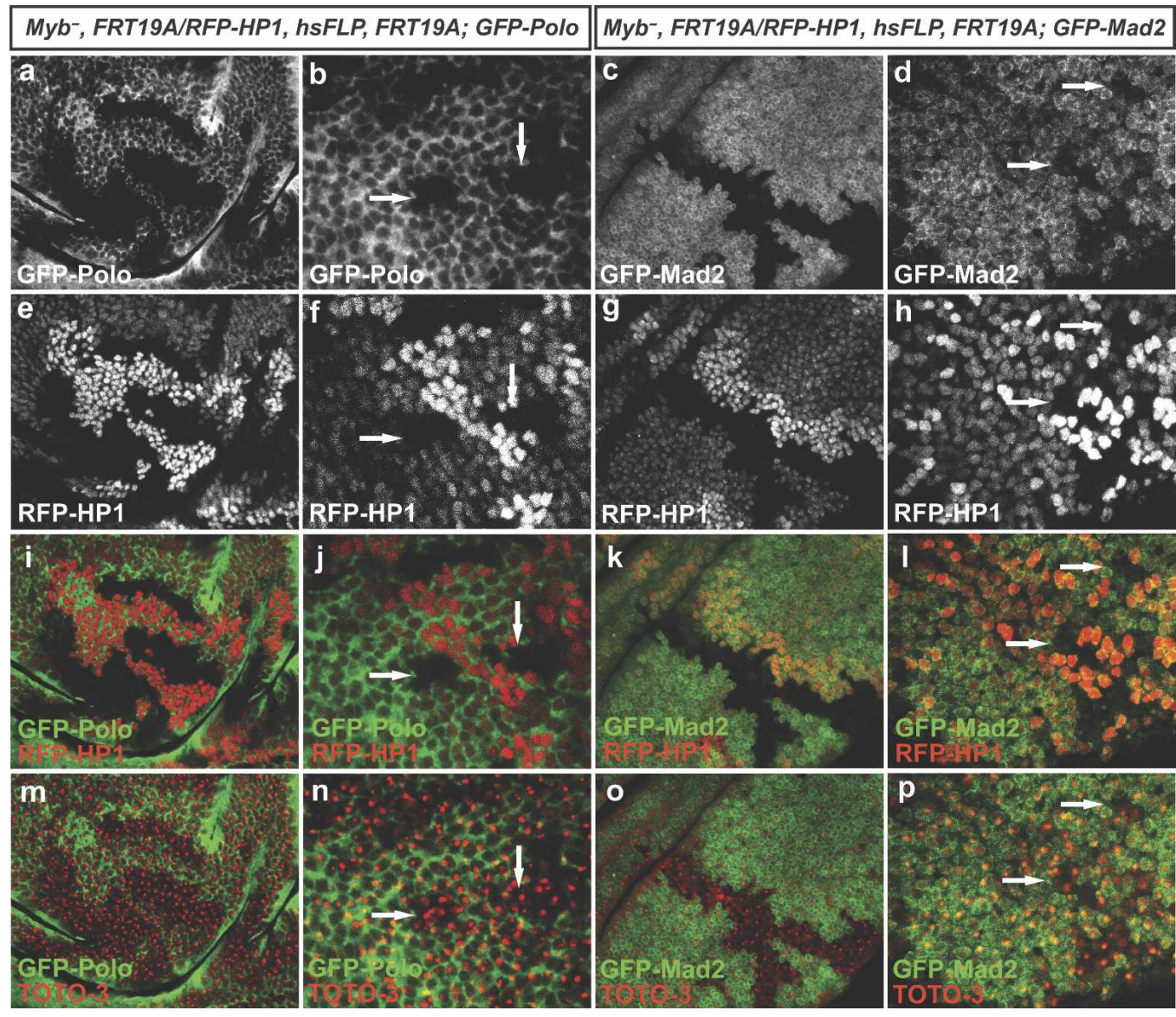

Figure 2. Mosaic analysis of Polo and Mad2 regulation by Myb. Imaginal wing discs from heterozygous larvae $\left(M y b^{+}, R F P-H P 1^{+} /\right.$ $\left.M y b^{-}\right)$in which mutant clones $\left(M y b^{-} / M y b^{-}\right)$and adjacent twin spots $\left(M y b^{+}, R F P-H P 1^{+} / M y b^{+}, R F P-H P 1^{+}\right)$were generated by mitotic recombination induced by hs-FLP. Each column displays the same imaginal disc via fluorescence of indicated GFP fusion proteins expressed from native promoters (panels $a-d$ ), of the RFP-HP1 clonal marker (panels $e-h$ ), of the merge of GFP and RFP (panels $i-1$ ), and of the merge of indicated GFP fusion protein fluorescence with that of the DNA dye TOTO-3 (panels $m-p$ ). The first and third columns display larger clones at lower magnification, whereas the second and fourth columns display smaller clones at higher magnification. Arrows indicate representative $M y b$ mutant clones. 
experiments demonstrated that altered levels of the RFPHP1 marker itself in a $M y b$ wild-type background caused no change in GFP-Polo or GFP-Mad2 (data not shown). Mutant clones $\left(R F P^{-}, M y b^{-} / R F P^{-}, M y b^{-}\right)$were similar in size to adjacent "twin spots" $\left(R F P^{+}, M y b^{+} / R F P^{+}, M y b^{+}\right)$, demonstrating that greatly decreased levels of Polo and SAC components do not inhibit cell proliferation in the short term. In summary, these results imply that $\mathrm{Myb}$ is required for the maintenance of normal levels of Polo and Mad2, and that the GFP-Polo and GFP-Mad2 proteins themselves are degraded during each mitotic cell cycle.

\section{The highly conserved Myb DNA-binding domain} is not required for activating gene expression in vivo

The Myb DNA-binding domain has been highly conserved during the evolution of animals, green plants, protists, and cellular slime molds (Davidson et al. 2004). Remarkably, the $\sim 150$-amino-acid Myb domain displays a $65 \%$ identity between the human and Dictyostelium proteins (Stober-Grasser et al. 1992). To determine the role of this domain in vivo, we constructed transgenic Drosophila in which the $\mathrm{C}$ terminus of Myb completely lacking the DNA-binding domain was fused to GFP. To our surprise, we found that this $\mathrm{C}$-terminal protein fragment rescued a uniformly lethal $M y b$-null mutant to adult viability, albeit at a lower frequency than a wildtype Myb protein (Supplemental Table S1). To determine whether this C-terminal Myb fragment was capable of regulating gene expression in vivo, we expressed either a full-length GFP-Myb fusion protein or the GFP C-terminal fusion protein in the posterior compartments of $M y b$-null imaginal wing discs in the presence of an RFP$M a d 2$ transgene. Both full-length Myb and the C-terminal Myb fragment were capable of activating RFP-Mad2 expression (Fig. 3A, panels a,d). The C-terminal Myb fragment lacking a DNA-binding domain was also capable of suppressing the increased frequency of H3S10phospho (PH3)-positive cells and partial chromosome condensation that occurs in vivo in $M y b$-null cells (Fig. 3A, panels c,f; Manak et al. 2007).

We next asked whether this C-terminal Myb protein fragment can assemble into MMB/dREAM complexes. Flag-tagged versions of either full-length Myb or the C-terminal fragment lacking a DNA-binding domain were expressed in Drosophila S2 cells, and immunoprecipitations with anti-Flag antibodies were performed on nuclear extracts. Both full-length Myb and the C-terminal fragment lacking a DNA-binding domain specifically coprecipitated Mip130, Mip120, Mip40, p55CAF1, and E2F2 (Fig. 3B). In summary, the highly conserved Myb DNA-binding domain is not required for association with the MMB/dREAM complex, activation of gene expression in vivo, or rescue of chromosome condensation defects that occur in the absence of Myb.

Variegation of GFP-Polo expression in the absence of both Myb and Mip130

Although Myb-null mutants are lethal and Mip130 mutants are viable, the lack of both Myb and Mip130 re-
A
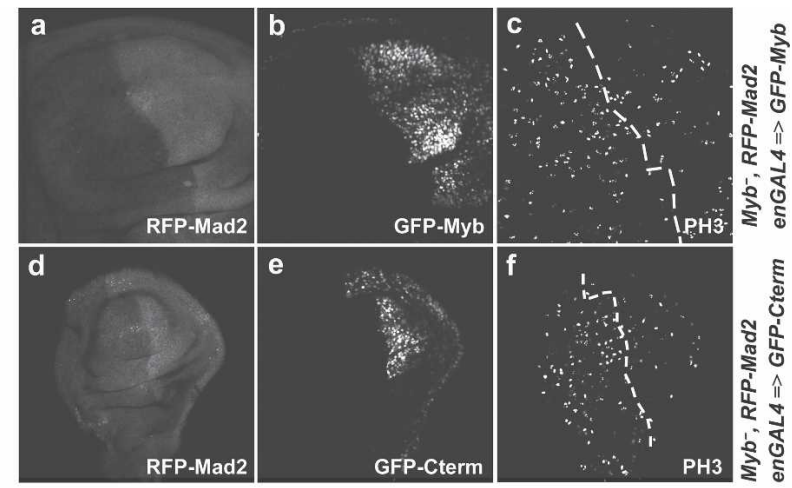

B
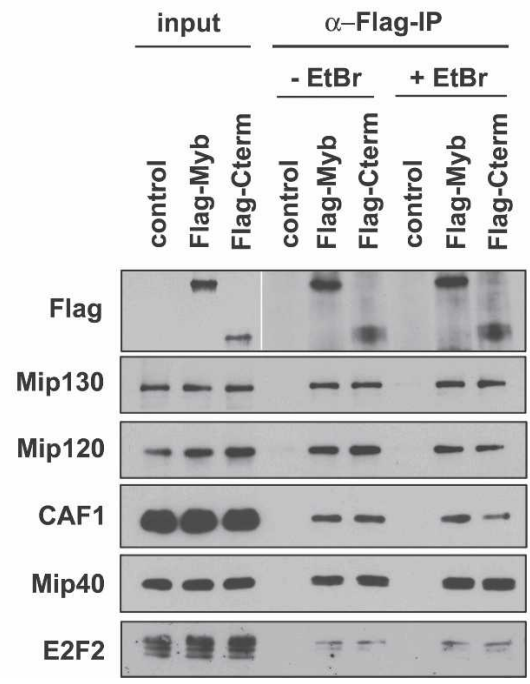

Figure 3. The Myb DNA-binding domain is not required for regulation of gene expression, for progression of chromosome condensation, or for entering the MMB/dREAM complex. $(A)$ Imaginal wing discs from $M y b$-null larvae in which either a GFP full-length Myb fusion protein (panels $a-c$ ) or GFP C-terminal Myb fusion protein lacking a DNA-binding domain (panels $d-f$ ) were expressed in the posterior compartment via the GAL4UAS binary system. Each row displays the same imaginal disc using three different markers: RFP-Mad2 visualized by staining with anti-RFP antibody (panels $a, d$ ), GFP-Myb fusion (panels $b, e)$, or anti-histone PH3 antibody (panels $c, f)$. $(B)$ Coimmunoprecipitation with anti-Flag M2 antibody \pm ethidium bromide (EtBr) in Drosophila S2 cells transfected with full-length FlagMyb, Flag-C-terminal Myb, or control vector. Stability of these interactions in the presence of ethidium bromide implies that these protein-protein interactions are not dependent on DNA (Lai and Herr 1992). Western blotting was performed with indicated antibodies. Input represents $5 \%$ of total.

stores viability (Beall et al. 2004). In the absence of Myb, the remaining members of the Myb complex might act together as an unrestrained repressor of the Polo and SAC genes, thereby resulting in mitotic defects. This model predicts that (1) loss of Myb but not Mip130 alone would reduce Polo and SAC gene expression; and (2) loss of both Myb and Mip130 would restore expression of Polo and SAC genes in vivo. As expected, GFP-Polo expression was uniformly decreased in $M y b$ single mutant, but not in Mip130 single mutant imaginal discs (Fig. 4A). 
GFP-Polo expression was, indeed, observed in $M y b$, Mip130 double mutant imaginal discs, as predicted. Unexpectedly, the Myb, Mip130 double mutant imaginal discs displayed a variegated pattern of fluorescence in which clusters of adjacent cells alternatively expressed either high or low levels of GFP-Polo (Fig. 4A). Similar variegation was observed with two independent insertions of the GFP-Polo transgene. These insertions have been mapped by inverse PCR and DNA sequencing to euchromatic regions of the genome at cytological bands 45D (in CG13955) on Chromosome II and 76D1 (between Fibp and Deaf1) on Chromosome III. Discovery of this variegated expression was possible because GFPPolo functions as a visible, cell-autonomous marker with single-cell resolution. In contrast, cell-by-cell resolution of gene expression is difficult to achieve by RNA in situ hybridization in imaginal wing discs.

Ectopic Myb suppresses and Mip130 enhances the variegation of GFP-Polo expression

In wild-type imaginal wing discs GFP-Polo is ON, whereas variegated expression occurs in Myb, Mip130 double mutant tissue. By analogy with PEV, enhancers are genetic modifiers that increase the proportion of cells in the OFF state, whereas suppressors decrease the proportion of cells in the OFF state (Schotta et al. 2003). The expression of a $M y b$ cDNA in the posterior compartment of a Myb, Mip130 double mutant imaginal wing disc suppressed the variegated pattern of GFP-Polo, resulting in uniformly high levels consistent with stabilization of this gene in the ON state (Fig. 4B, panels a-c). Myb protein has been shown to be destabilized in the absence of Mip130 (Beall et al. 2004). However, our results imply that at sufficiently high levels, Myb can function in a Mip130-independent fashion to regulate Polo gene expression. No alteration in GFP-Polo expression was observed when Myb was ectopically expressed in wild-type imaginal wing discs (data not shown). Taken together, these results imply that the MMB/dREAM complex, and that Myb in particular, is required for the epigenetic maintenance of Polo expression.

The expression of Mip130 in the posterior compartment of a Myb, Mip130 double mutant imaginal wing disc enhanced the variegated pattern of GFP-Polo expres-
Figure 4. Myb suppresses and Mip130 enhances the variegation of GFP-Polo expression. (A) Expression of GFP-Polo in imaginal wing discs from single or double mutant genotypes as indicated. $(B)$ Imaginal wing discs from double mutant larvae in which RFP-Myb, Mip130 alone, or RFP and Mip130 were expressed in the posterior compartment via the GAL4-UAS binary system as indicated. Each row displays the same imaginal disc using two different markers (first and second columns) and a merged image (third column). (Panels $a-c$ ) $M_{y} b^{-}, M i p 130^{-}$disc with GFP-Polo and UAS-RFP-Myb. (Panels $d-f$ ) Myb- ${ }^{-}$, Mip130disc with GFP-Polo and UAS-Mip130 visualized by anti-Mip130 antibody. (Panels g-i) Myb $^{-}$, Mip130- larvae with UAS-RFP and UAS-Mip130 stained with anti-histone PH3 antibody. Note variegation of GFPPolo expression only in the Myb,Mip130disc $(A)$ and unrescued anterior compartments of such discs $(B)$.
A
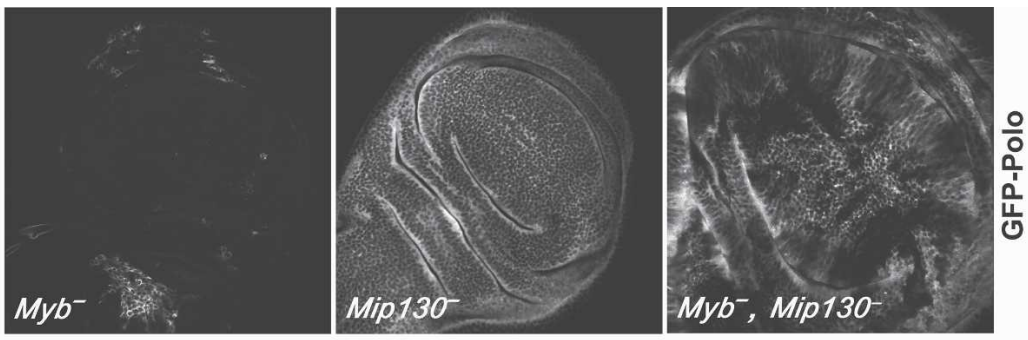

B
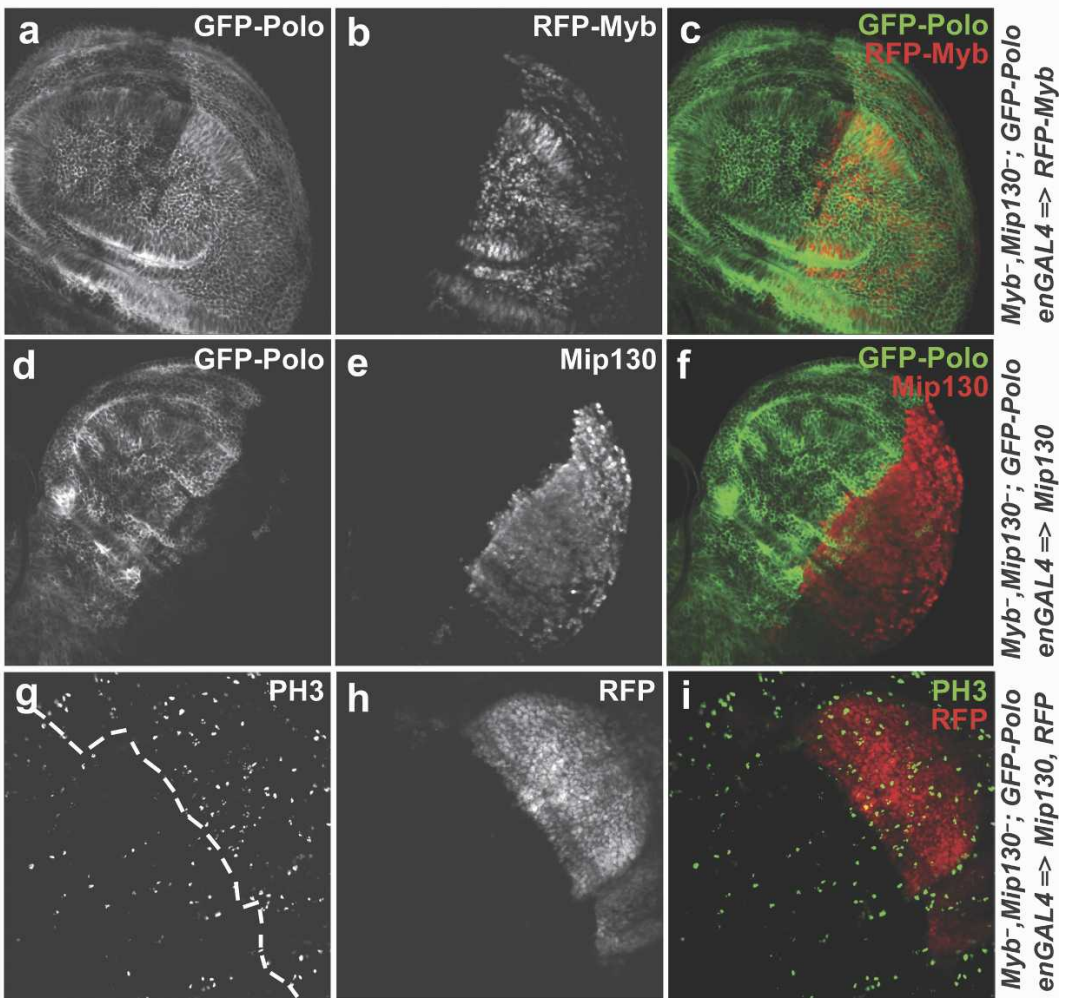
sion, in this case resulting in uniformly low levels consistent with stabilization of this gene in the OFF state (Fig. 4B, panels d-f). Ectopic Mip130 had no effect on GFP-Polo expression in a wild-type or a Mip130 mutant background (data not shown). Although Myb and Mip130 also opposed one another in regulating the expression of GFP-Mad2 and GFP-Rod, no variegation of these genes was observed in Myb, Mip130 double mutants (Supplemental Fig. S2; data not shown).

A marked increase in the frequency of PH3-positive cells was observed when a Mip130 cDNA was expressed in the posterior compartment of a Myb, Mip130 double mutant imaginal wing disc (Fig. 4B, panels g-i). The increased frequency of partial chromosome condensation was similar to that seen in Myb-null mutant cells in comparison with adjacent $M y b$-rescued cells (Manak et al. 2007). These results demonstrate that the mitotic defects in $M y b$-null cells are dependent on the presence of Mip130.

E2F2-RBF represses the expression of Polo and the $S A C$

To test whether E2F2-RBF also regulates the Polo and SAC genes, we decided to focus on E2F2 for two reasons. First, E2F2 but not E2F1 is present in the MMB/dREAM complex. Because DP associates with both E2F1 and E2F2, loss of DP is equivalent to loss of both E2F1 and E2F2 (Frolov et al. 2001). Second, although RBF2 has been reported to have some preference for E2F2 over E2F1, both RBF1 and RBF2 can bind to and repress gene expression via E2F2 (Dimova et al. 2003).

In contrast to the results with Myb and Mip130, the ectopic expression of E2F2 in the posterior compartment of an otherwise wild-type wing imaginal disc was sufficient to repress the expression of Polo-GFP (Fig. 5B, panels a-c). In an E2F2-null background, the baseline expression of Polo-GFP appeared to be elevated, and the expression of E2F2 in the posterior compartment caused a nearly complete loss of Polo-GFP expression (Fig. 5B, panels d-f). Similar observations were made with Mad2GFP (Supplemental Fig. S3). The expression of RBF2, a corepressor for E2F2, also decreased the expression of GFP-Polo in otherwise wild-type imaginal discs (Fig. 6df). Effects of RBF1 were difficult to assess because of increased cell death caused by its ectopic expression (Fig. 6a-c; Neufeld et al. 1998). Ectopic expression of E2F1 in a wild-type background had no effect on GFP-Polo or GFP-Mad2 levels, even in the presence of ectopic DP (Fig. 6g-i). Together these results imply that E2F2 is a limiting factor in the repression of Polo and Mad2 gene expression in vivo. Furthermore, these results suggest that Myb and E2F2 play adversarial roles in the regulation of Polo and Mad2. Additional evidence for an adversarial role of Myb and E2F2 in vivo was provided by the observation that the slow growth phenotype of $M y b$-null larvae can be suppressed in Myb, E2F2/+ mutants (Supplemental Fig. S3). These results are reminiscent of the suppression of the slow growth phenotype of larvae mutant for E2F1 in E2F1, E2F2 double mutants (Frolov et al. 2001).

Because MMB/dREAM contains three different DNAbinding proteins (Myb, Mip120, and E2F2) and a putative AT-hook protein (Mip130), we hypothesized that Polo and Mad2 might be direct targets of transcriptional regulation by the complex. To test whether these proteins were present at the promoters of Polo and Mad2, we turned to a simpler experimental system, the Drosophila S2 cell line. We first verified that the regulation of the Polo and Mad2 genes by Myb that we had observed in vivo could be modeled by RNAi depletion in S2 cells (Supplemental Fig. S4). We then performed chromatin immunoprecipitation (ChIP) in S2 cells and found that Myb, Mip130, Mip120, Mip40, and E2F2 all specifically occupied the Polo promoter (Fig. 5C,D). Similar observations were made with the Mad2 and Rod promoters (Supplemental Fig. S5). In contrast to Polo and the SAC genes above, BubR1 appears to be indirectly regulated by

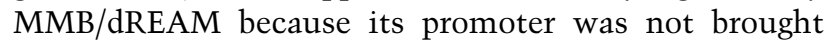
down in similar ChIP assays and its expression was not altered by RNAi depletion of Myb. Taken together, these results are consistent with a role for MMB/dREAM complexes in directly regulating transcription of Polo, Mad2, and Rod.

\section{Variegation of GFP-Polo expression in the absence} of Myb and E2F2

In $M y b$, E2F2 double mutant imaginal wing discs, GFPPolo again displayed a variegated pattern of expression (Fig. 5A). The OFF state of expression in $M y b, E 2 F 2$ double mutants was even lower than that observed in Myb, Mip130 double mutants, suggesting that perhaps the loss of Mip130 abolishes the action of some but not all E2F2-RBF. The expression of Myb in the posterior compartment of $M y b, E 2 F 2$ double mutant imaginal wing discs strongly suppressed GFP-Polo variegation, resulting in a nearly uniform population of cells in the ON state (Fig. 5B, panels g-i).

\section{Discussion}

Regulation of mitosis by Myb and E2F2-RBF via the MMB/dREAM complex

We characterized the mitotic abnormalities that occur in the absence of $M y b$ by real-time live microscopy of mutant larval neuroblasts. Our results confirmed and extended previous studies of fixed tissues and pointed toward specific candidate genes that are dependent on Myb for their expression in vivo. In particular, we found that Myb and E2F2-RBF act in opposition to directly regulate the expression of Polo and a subset of SAC genes in vivo. The E2F-RB axis has been intensively studied as a regulator of gene expression that controls the G1-S transition of the cell cycle in vertebrates and in Drosophila (Duronio et al. 1995; Dimova and Dyson 2005). Our results demonstrate that in Drosophila, Myb acts in opposition 
Figure 5. E2F2 enhances the variegation of GFP-Polo expression. (A) Expression of GFP-Polo in imaginal wing discs from wild-type (wt), from E2F2-null, and from $M y b, E 2 F 2$ double-null genotypes as indicated. $(B)$ Imaginal wing discs from wildtype (panels $a-c$ ), E2F2-null (panels $d-f$ ), and $M y b, E 2 F 2$ double-null (panels $g-i$ ) mutant larvae in which RFP and either E2F2 or Myb were expressed in the posterior compartment via the GAL4-UAS binary system. Each row displays the same imaginal disc using two different markers (first and second columns) and a merged image (third column). $(C, D)$ ChIP of Polo promoter and coding region DNA from Drosophila S2 cells by the indicated antibodies or a control (IgG). Occupancy values were determined by real-time PCR. Error bars indicate standard deviation of three independent experiments.
A
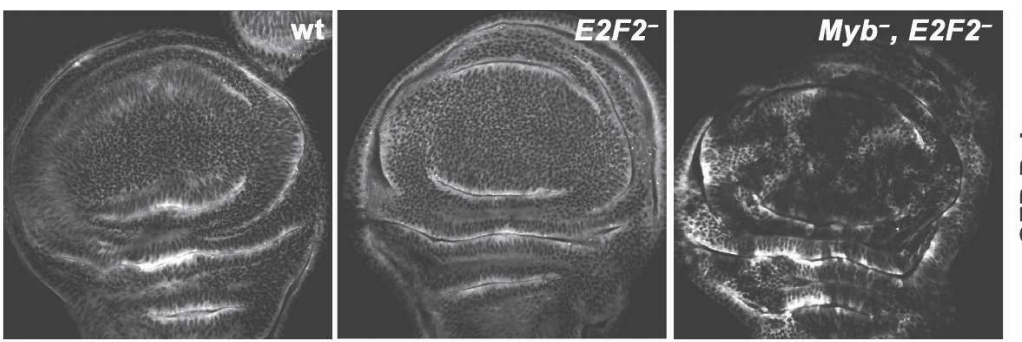

응
$\frac{1}{1}$
$\frac{1}{4}$
0
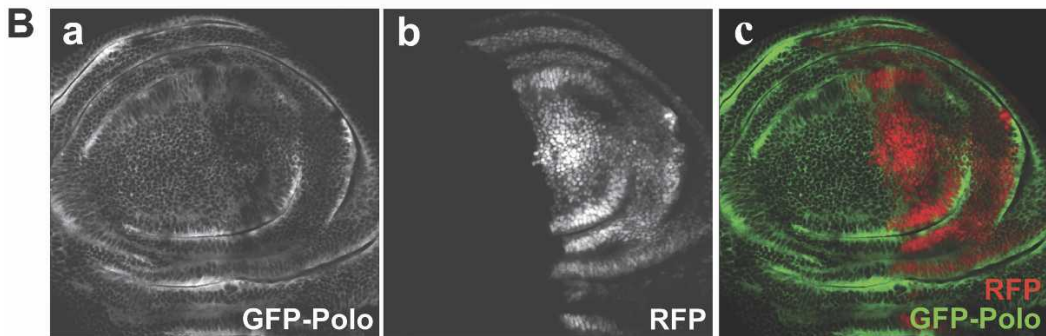

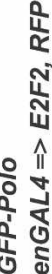
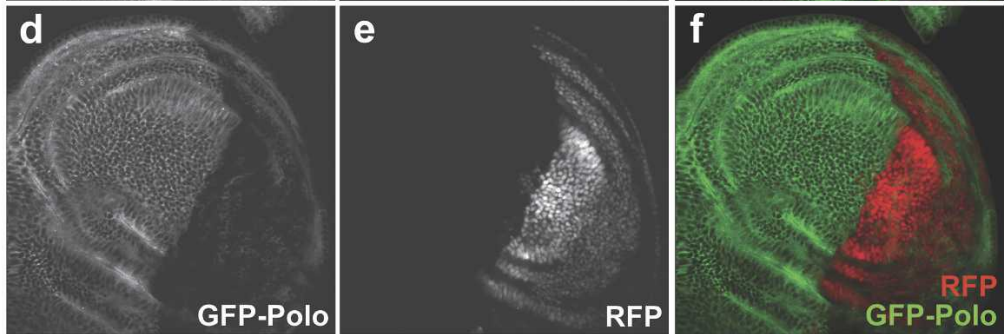

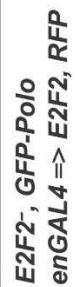
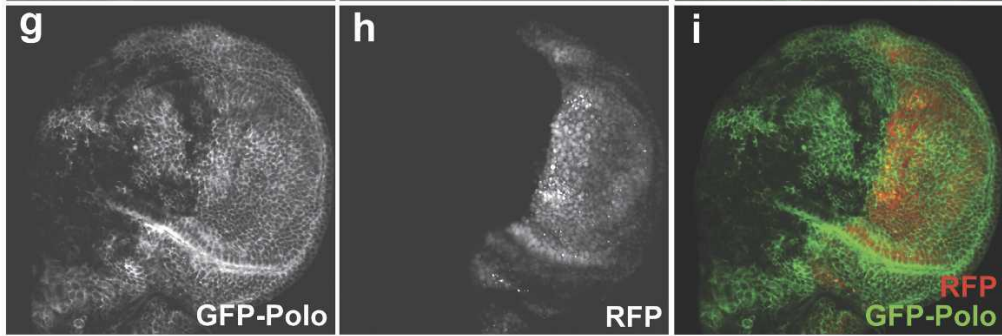

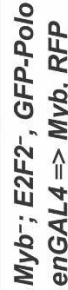
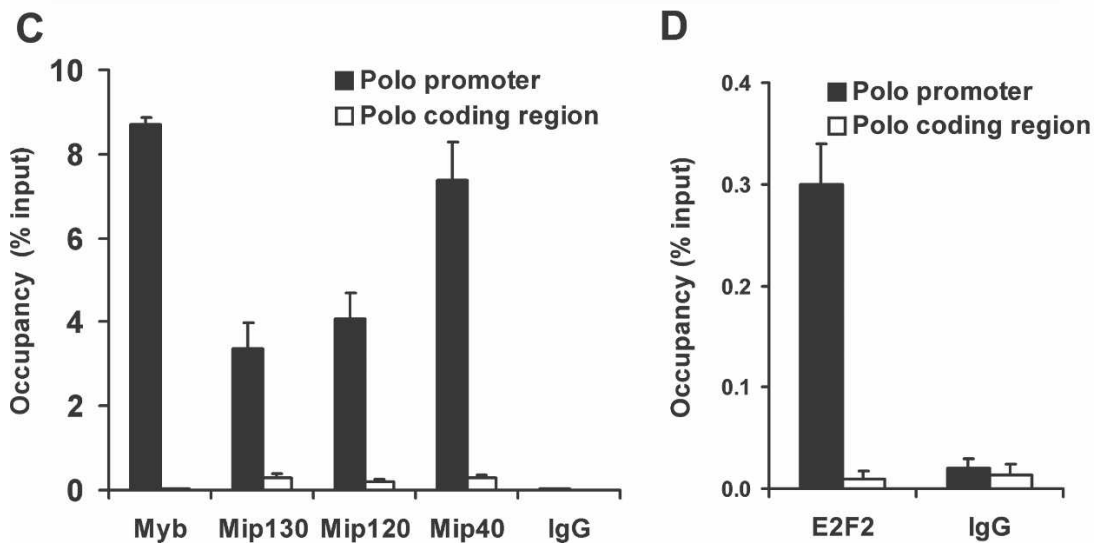

to both E2F2-RBF and Mip130 to control key regulators of the G2/M and intra-M-phase transitions, including Polo kinase and the SAC. Our results therefore provide a molecular explanation for the mitotic abnormalities that occur in the absence of Drosophila Myb (Fung et al. 2002; Manak et al. 2002).

Our observations in Drosophila are supported by studies in vertebrate cell culture showing that E2F4, the ver- tebrate homolog of Drosophila E2F2, occupies promoters of G2/M regulators including $M A D 2$, which is constitutively activated in $p 107, p 130$ double mutant fibroblasts (Ren et al. 2002). Similar observations were made in $R b$ mutant fibroblasts and in cells expressing the adenovirus E1A protein, an inhibitor of all three Rb-related proteins (Hernando et al. 2004). Recently, several laboratories have reported that E2F4 in vertebrate cells is present in 

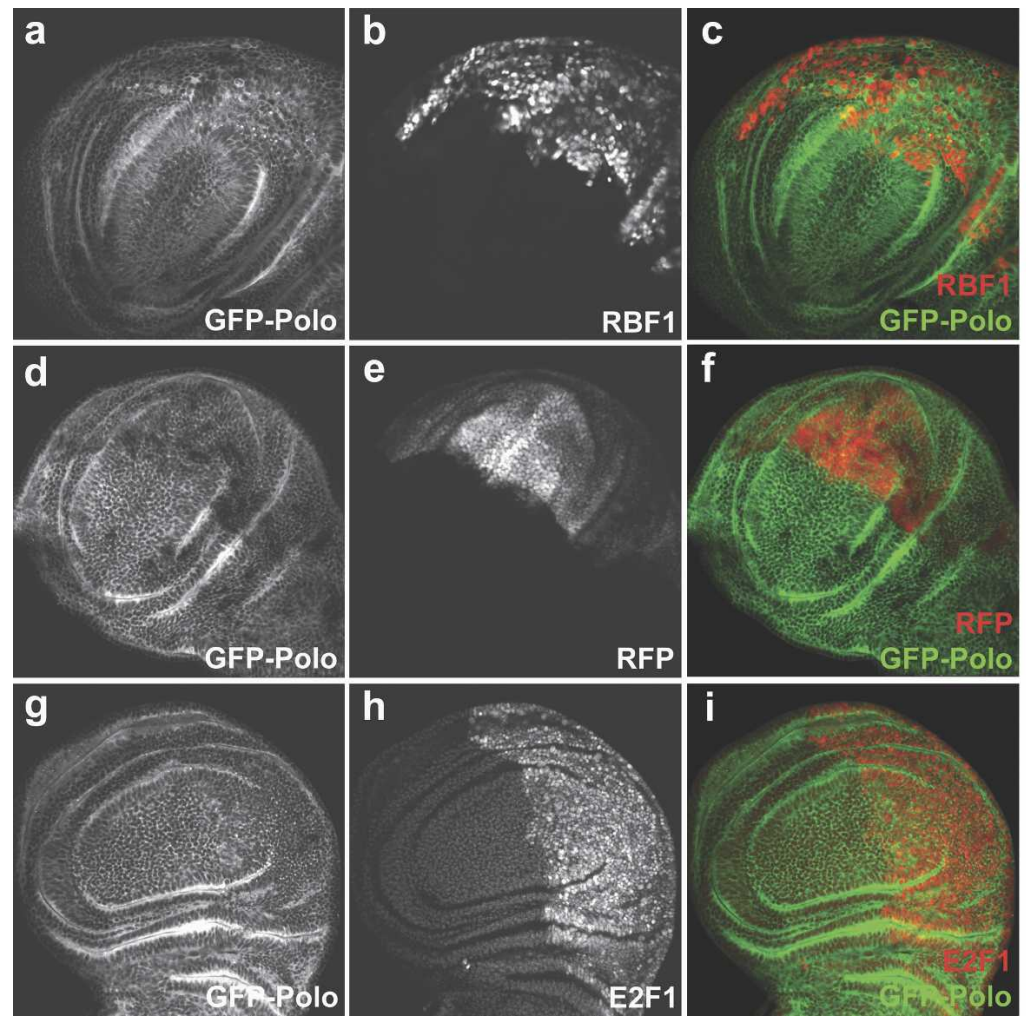

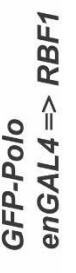

$\frac{\frac{0}{\alpha}}{\frac{1}{4}}$

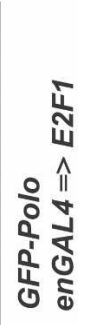

Figure 6. RBF2 represses Polo expression in vivo. Imaginal wing discs from larvae in which the RBF1 $(a-c), \operatorname{RBF} 2$ and RFP $(d-f)$, or both the E2F1 and DP $(g-i)$ proteins were expressed in the posterior compartment via the GAL4-UAS binary system. Each row displays the same imaginal disc using two different markers (first and second columns) and a merged image (third column). ( $a-c$ ) GFP-Polo and RBF1 visualized by anti-RBF1 antibody. Compartment-specific GFP-Polo expression was difficult to assess due to increased apoptosis caused by increased levels of RBF1 in the posterior compartment. $(d-f)$ GFP-Polo and RBF2 coexpressed with RFP. Note the decreased expression of GFP-Polo in the posterior compartment expressing elevated levels of RBF2 and RFP. $(g-i)$ GFP-Polo and E2F1 coexpressed with DP and visualized with antiE2F1 antibody. No significant alteration of GFP-Polo expression was seen in the posterior compartment expressing elevated levels of E2F1 and DP.
MMB/dREAM-like complexes (Korenjak et al. 2004; Litovchick et al. 2007; Pilkinton et al. 2007; Schmit et al. 2007). Our observations that Myb acts in opposition to E2F2-RBF in Drosophila by activating Polo and SAC gene expression, together with our previous finding that vertebrate B-Myb can complement cell cycle defects in Drosophila Myb-null hemocytes, imply a similar role for B-Myb in vertebrates (Davidson et al. 2005).

\section{$\mathrm{B}-\mathrm{Myb}$ and cancer}

The role of $B-M y b$ in oncogenesis has been paradoxical. Elevated levels of $B-M y b / M Y B L 2$ expression correlate with poor prognosis in a variety of human cancers (Amatschek et al. 2004; Paik et al. 2004). In contrast, loss-offunction mutants of Drosophila Myb and of zebrafish $B-M y b$ increase the frequency of abnormal mitoses and aneuploidy, hallmarks of cancer cells (Fung et al. 2002; Manak et al. 2002; Shepard et al. 2005). Similarly paradoxical observations have been made for $M A D 2$, in that loss-of-function mutants cause genomic instability, whereas increased expression correlates with poor prognosis in human cancer. The expectation was that lossof-function mutants of SAC genes might be a frequent cause of human cancer (Kops et al. 2005). Although such mutations have been reported, they appear to be the exception rather than the rule. Surprisingly, either increased or decreased levels of MAD2 expression in mice cause genomic instability and cancer (Michel et al. 2001; Sotillo et al. 2007). Polo kinase has yet to be analyzed in such detail. However, increased levels of Polo expression do correlate with poor prognosis in human cancers (Takai et al. 2005). Myb proteins have also been reported to regulate the expression of mitotic cyclins in animals and in plants (Ito et al. 2001; Okada et al. 2002; Zhu et al. 2004). The correlation of increased expression of $B-M y b$ with poor prognosis in human cancer is therefore predicted to result from aberrant expression of $\mathrm{G} 2 / \mathrm{M}$ regulators including Polo and the SAC genes.

\section{Functional domains of Myb and evolution of the Myb-MuvB/dREAM complex}

Surprisingly, the highly conserved DNA-binding domain of Drosophila Myb was not required for assembly of $\mathrm{Myb}$ into $\mathrm{MMB} / \mathrm{dREAM}$, for transcriptional regulation in vivo, or for rescue of $M y b$-null mutants to viability. Two extreme models that might explain these results are that (1) the Myb DNA-binding domain is not required for positively regulating gene expression or cell cycle progression as implied by our results with MAD2 (Fig. 3, panels $\mathrm{d}-\mathrm{f}$ ); and (2) the DNA-binding domain-deficient mutant acts as a dominant-negative and permits partial rescue but not robust viability, similar to that seen in double mutants of Myb together with Mip130, Mip120, or Mip40 (Beall et al. 2004, 2007). The truth probably lies somewhere in between. The complex and varied nature of gene regulation by $\mathrm{MMB} / \mathrm{dREAM}$ has been demonstrated in a recent genome-wide analysis of alterations in gene expression following RNAi-mediated knockdown of individual proteins in the complex in a hemocytic cell line (Georlette et al. 2007). 
Our results did prompt us to further probe the evolutionary origins of $\mathrm{Myb}$ and the MMB/dREAM complex. The genome of the nematode $C$. elegans encodes all members of the MMB/dREAM complex excepting Myb (Lipsick 2004). However, simpler eukaryotes including cellular slime molds and protists do contain conserved Myb DNA-binding domains. These results led us to speculate that nematodes had lost the $M y b$ gene during evolution. Consistent with this hypothesis, analysis of the recently published genome of the sea anemone Nematostella, a member of the oldest eumetazoan phylum (Cnidaria), reveals the presence of a $M y b$ gene that encodes a protein homologous to vertebrate B-Myb and Drosophila Myb (Supplemental Fig. S6). In addition to the Myb DNA-binding domain, the predicted sea anemone $\mathrm{Myb}$ protein includes highly conserved regions of the $\mathrm{C}$ terminus that are not present in slime mold and protist Myb proteins. The evolutionary conservation of the $\mathrm{C}$ terminus is consistent with our finding that the DNA-binding domain of Drosophila Myb is not required for some essential functions of the Myb protein in vivo. Remarkably, the Nematostella genome also encodes homologs of Mip130, Mip120, Mip40, E2F, and RBF. These results imply that the $\mathrm{MMB} / \mathrm{dREAM}$ complex existed in the common ancestor of all eumetazoans and that nematodes have indeed lost Myb during their subsequent evolution.

Epigenetic regulation of gene expression by $M y b$, Mip130, and E2F2-RBF

Only by studying gene expression at the single-cell level in intact tissues were we able to establish a role for the $\mathrm{MMB} / \mathrm{dREAM}$ complex in the epigenetic regulation of gene expression. In classical position effect variegation $(\mathrm{PEV})$, the white-mottled alleles of Muller were caused by X-ray-induced chromosomal inversions and translocations that brought the normally euchromatic white and Notch genes adjacent to constitutive heterochromatin (Muller 1930). These and other variegating alleles have been instrumental in understanding the establishment and maintenance of constitutive heterochromatin (Eissenberg and Wallrath 2003). In particular, the isolation of enhancers and suppressors of PEV led to the identification of key epigenetic regulators including an H3K9 methylase [Su(var)3-9], the major H3K9 methyl-binding protein HP1 [Su(var)2-5], and an H3K4 demethylase [Su(var)3-3] that acts upstream of H3K9 methylation (Schotta et al. 2003; Rudolph et al. 2007). The normal function of these genes and the proteins they encode is clearly not the modification of PEV. Nevertheless, their function in the context of these unusual white alleles has been extremely informative about their function in normal gene regulation.

By analogy, we believe that our studies of Polo variegation using single and double mutants of the $\mathrm{MMB} /$ dREAM complex are similarly informative about the functions of these proteins in normal gene regulation. Although Myb scores as an "activator" in that Polo expression is extinguished in its absence, Myb is actually not required for Polo expression in the absence of both Myb and Mip130, or of both Myb and E2F2. Remarkably, Polo expression in such double mutants displays a variegation that fulfills the current definition of epigenetic phenomena in that (1) genetically identical cells display heritable phenotypic differences; (2) these phenotypes exhibit a switch-like behavior; and (3) these phenotypes are stably maintained through successive cell divisions in the absence of an extrinsic signal (Gottschling 2004). From our results, we infer that Myb is required for the stable maintenance of the Polo ON state. Conversely, Mip130 and/or E2F2 are required for the stable maintenance of the Polo OFF state (Fig. 7).

We note that the normal state of Polo expression in late third instar imaginal wing discs is ON. This state is stably maintained in Mip130 and in E2F2 single mutants, consistent with the viability of adult animals of these genotypes (Cayirlioglu et al. 2001; Frolov et al. 2001; Beall et al. 2004). In contrast, $M y b$-null mutants fail to maintain expression of Polo, consistent with their larval lethal phenotype (Manak et al. 2002). In this regard, other members of the complex were properly targeted to the Polo promoter in the absence of Myb in RNAi-treated S2 cells (data not shown). Although $M y b$, Mip130 double mutants can survive to adulthood, their viability is severely compromised (Beall et al. 2004). The epigenetic instability of Polo expression in double mutant imaginal wing discs is consistent with this impaired viability. Presumably, sufficient cell proliferation occurs during development via those epigenetic clones with Polo in the ON state in order to permit survival to adulthood of some Myb, Mip130 double mutant animals. However, the loss of those epigenetic clones with Polo in the OFF state, either during development or during renewal of essential adult tissues such as the gut and immune system, results in poor overall viability.

We expect that other genes in addition to Polo will display a similar epigenetic regulation by MMB/dREAM. However, the magnitude and direction of such regulation may differ from gene to gene, and from cell type to cell type. In this regard, RNAi knockdown studies in two Drosophila hemocyte cell lines have shown that proteins of the MMB/dREAM complex regulate an unexpectedly large number of genes with widely divergent biological functions (Dimova et al. 2003; Georlette et al. 2007). In addition, the MMB/dREAM complex was found to be present proximal to the promoters of approximately one-third of all genes in a single cell line (Georlette et al. 2007).

The variegation of GFP-Polo expression observed in Myb, Mip130 and in Myb, E2F2 double mutants does not appear to be classical PEV for two reasons. First, we found that the loss of $M y b$ itself neither enhances nor suppresses classical PEV (Supplemental Fig. 7S). Secondly, two independent insertions of the same GFP-Polo transgene gave similar patterns of expression in $M y b$, Mip130 double mutant larvae. These euchromatic insertion sites are not consistent with classical PEV, which occurs when normally euchromatic genes are placed adjacent to constitutive heterochromatin. Interestingly, $\mathrm{Rb}$ 

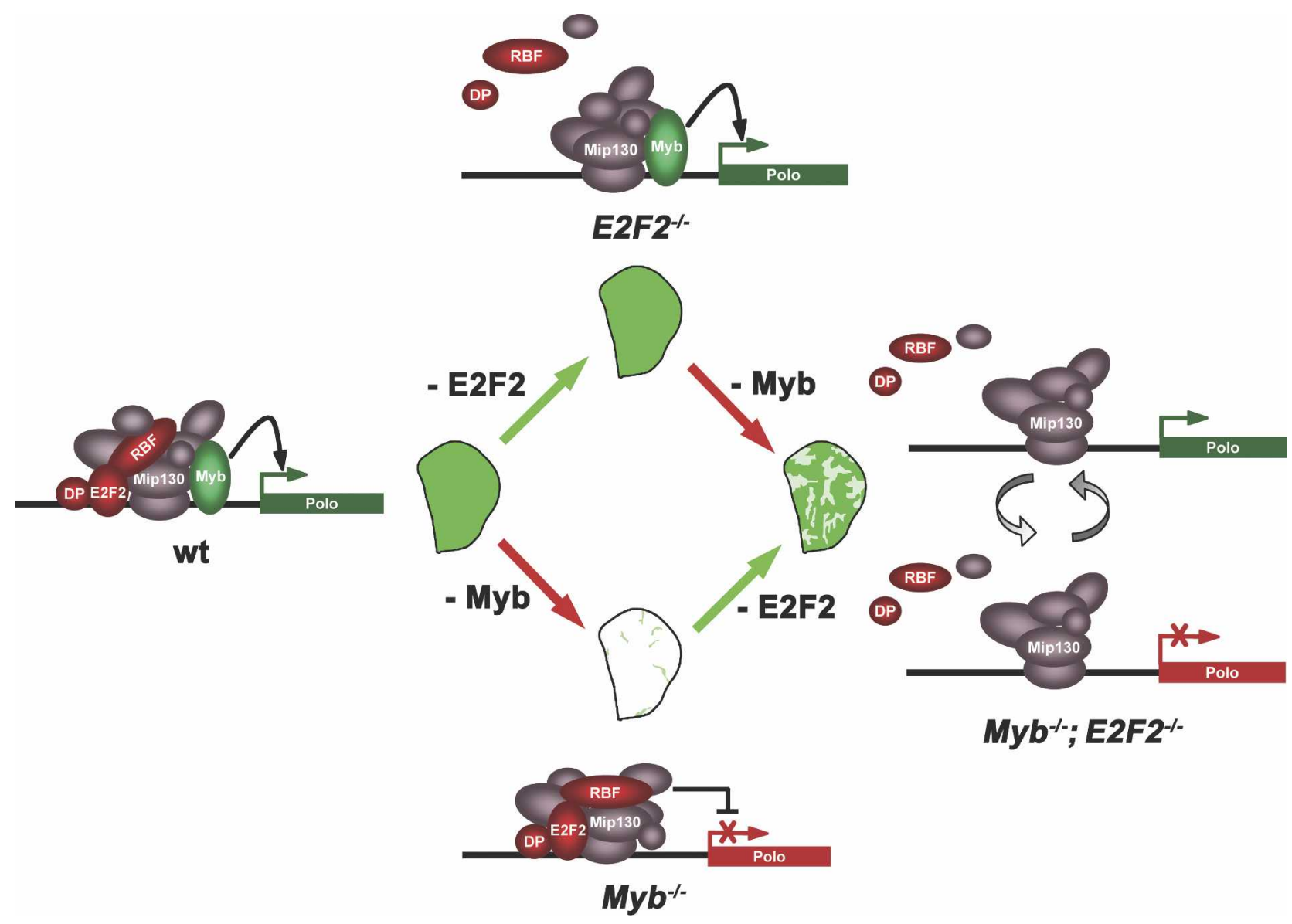

Figure 7. Epigenetic regulation of GFP-Polo by Myb and E2F2-RBF. In wild-type imaginal wing discs, the entire MMB/dREAM complex is present at the Polo promoter, the gene is ON, and all cells are GFP-positive. In the E2F2-null mutant, DP and RBF proteins are also absent from the Polo promoter, but the gene remains ON, and all cells are GFP-positive. In the $M y b$-null mutant, the remainder of the complex is present at the Polo promoter, the gene is OFF, and almost all cells are GFP-negative. In the Myb, E2F2 double mutant, the gene switches between epigenetically stable ON and OFF states. The diagram implies that additional corepressors are dependent on RBF for their recruitment, possibly the HDAC1 or L(3)MBT subunits of the larger MMB complex (Lewis et al. 2004). A similar model can be drawn to explain the data for Myb and Mip130 single and double mutants (not shown).

family proteins have been proposed to function in epigenetic regulation of gene expression (Nielsen et al. 2001; Vandel et al. 2001; Gonzalo et al. 2005; Kotake et al. 2007). However, until now direct evidence for such regulation in vivo had been lacking.

Our own results together with those cited above suggest a role for the MMB/dREAM complex in genomewide epigenetic control, perhaps via the regulation of the facultative heterochromatin that is widely dispersed among bulk euchromatin. We speculate that the specific loss of $M y b$ during the evolution of nematodes may be directly related to the absence of heterochromatin in this organism. In addition, our results support the hypothesis that the mutation of some oncogenes and tumor suppressor genes, including $M y b, M y c, E 2 F s$, and $R b$ family members, may cause cancer by a global disruption of epigenetic homeostasis rather than by activating or repressing a small number of critical target genes (Lipsick 2004; Gonzalo et al. 2005; Knoepfler et al. 2006).

\section{Materials and methods}

Fly strains and genetics

Flies were raised on cornmeal-molasses-agar medium at $25^{\circ} \mathrm{C}$ (Greenspan 1997). Meiotic recombination, UAS-GAL4 expression, and FLP-FRT mosaic analysis were performed using standard methods (Greenspan 1997). The genotypes used in this work are described in detail in the Supplemental Material. Transgenic flies were generated by standard methods using the plasmids described in the Supplemental Material.

\section{Time-lapse analysis of neuroblast cell division in larval brain}

Chromosomes were visualized using mRFP-histone H2avD under control of its native promoter (Pandey et al. 2005). Mitotic spindles and centrosomes were visualized using either the G147 gene trap expressing a GFP-tagged microtubule-associated protein (Morin et al. 2001), or GFP-TACC under control of Ubiquitin promoter (Barros et al. 2005). Details of live microscopy are provided in the Supplemental Material. 
Wen et al.

\section{Immunocytochemistry}

Experiments were performed as described, except that in some cases TOTO-3 (Molecular Probes) instead of ethidium bromide was used to visualize DNA (Manak et al. 2007). Images were taken using a PCM2000 laser scanning confocal microscope (Nikon) and processed using Adobe Photoshop with no $\gamma$-correction. Primary antibodies and dilutions used for immunostaining were as follows: rabbit and mouse anti-PH3 antibodies at 1:500 (Upstate Biotechnology), rabbit anti-Mip130 at 1:500 (from L. Beall), rabbit anti-RFP at 1:500 (from S. Heidmann), mouse antiRBF1 at 1:500, and rabbit anti-E2F1 at 1:500 (from N. Dyson).

\section{RNA fluorescence in situ hybridization (FISH)}

cDNA fragments ( 800 base pairs [bp]) of each target gene were amplified by PCR and subcloned into the pCR4-TOPO vector (Invitrogen). Linearized plasmids were used as templates for in vitro transcription. RNA probes were prepared by T7 or T3 RNA polymerase per the manufacturer's instructions (Roche). The $M y b$ probe was labeled with biotin, and probes for various other genes were labeled with digoxigenin. Two-color RNA FISH was performed simultaneously with $M y b$ and other gene probes as described (Wulbeck and Helfrich-Forster 2007). After hybridization, FISH signals were developed by sequential tyramide detection according to the manufacturer's protocols (TSA-Plus Cyanine 3/Fluorescein System; PerkinElmer LAS, Inc.).

\section{Cell culture and transfection}

Drosophila S2 cells were grown at $25^{\circ} \mathrm{C}$ in Schneider's Drosophila medium supplemented with $10 \%$ fetal bovine serum. Coding sequences for full-length $M y b$ and $M y b$-Cterm were amplified by PCR with upstream in-frame insertion of three tandem Flag epitope tags, then subcloned into the Ract-HAdh plasmid (Drosophila Genomic Resource Center, Bloomington, IN) to allow the expression under control of the actin $5 \mathrm{C}$ promoter. S2 cells were diluted to a final concentration of $1 \times 10^{6}$ cells per milliliter, and $30 \mu \mathrm{g}$ of Ract-HAdh-Flag-Myb, Ract-HAdh-FlagMyb-Cterm, or empty vector DNA were transfected using FuGene6 reagent (Roche). Cells were harvested $48 \mathrm{~h}$ after transfection for immunoprecipitation experiments.

\section{Immunoprecipitation and Western blots}

Nuclear extracts were prepared from the transfected S2 cells 48 $\mathrm{h}$ after transfection. Immunoprecipitation, SDS-PAGE, and Western blotting were performed as described in the Supplemental Material.

\section{ChIP}

ChIP was performed as described (O'Geen et al. 2006). For each ChIP experiment, $3 \times 10^{7} \mathrm{~S} 2$ cells were used. The following antibodies were used for ChIP assays: affinity-purified anti-Myb, anti-Mip130, anti-Mip120, and anti-Mip40; unpurified antidE2F2 rabbit serum; and rabbit anti-histone H3 (Abcam). Preimmune rabbit serum was used as a negative control. Genespecific PCR primers were designed to amplify the promoter and ORF sequences of indicated target genes; these primer sequences are available upon request. Real-time PCR was performed in triplicate on a PRISM 7700 Sequence Detection System using Power SYBR Green PCR Master Mix (Applied Biosystems).

\section{RNAi and quantitative RT-PCR}

Gene-specific PCR products ( 700 bp) flanked by T7 polymerase-binding sites were used as templates for in vitro transcrip- tion reactions. dsRNA was transfected into Drosophila S2 cells as described in the Supplemental Material.

For quantitative real-time RT-PCR, total RNA was isolated using the RNeasy Plus Mini Kit (Qiagen), and cDNA was synthesized using the SuperScript First-Strand Synthesis kit (Invitrogen). RT-PCR was then performed in triplicate using Power SYBR Green PCR Master Mix (Applied Biosystems). Gene-specific primers for real-time RT-PCR were designed with Primer Express software (Applied Biosystem); these primer sequences are available upon request.

\section{Acknowledgments}

We thank Xiaobing Shi for help with ChIP and real-time PCR analyses. We thank the members of our own laboratory and the Botchan laboratory for many helpful discussions, and the Bloomington Drosophila Stock Center, L. Beall, M. Botchan, W. Chia, W. Du, R. Duronio, N. Dyson, J. Eissenberg, S. Heidmann, J.Y. Huang, C. Lehner, T. Orr-Weaver, J. Raff, and C. Sunkel for providing reagents used in our experiments. This work was supported by research grant R01CA128836 from the USPHS (to J.S.L.) and by a McCormick Fellowship (to H.W.).

\section{References}

Amatschek, S., Koenig, U., Auer, H., Steinlein, P., Pacher, M., Gruenfelder, A., Dekan, G., Vogl, S., Kubista, E., Heider, K.H., et al. 2004. Tissue-wide expression profiling using cDNA subtraction and microarrays to identify tumor-specific genes. Cancer Res. 64: 844-856.

Barros, T.P., Kinoshita, K., Hyman, A.A., and Raff, J.W. 2005. Aurora A activates D-TACC-Msps complexes exclusively at centrosomes to stabilize centrosomal microtubules. J. Cell Biol. 170: 1039-1046.

Beall, E.L., Manak, J.R., Zhou, S., Bell, M., Lipsick, J.S., and Botchan, M.R. 2002. Role for a Drosophila Myb-containing protein complex in site-specific DNA replication. Nature 420: 833-837.

Beall, E.L., Bell, M., Georlette, D., and Botchan, M.R. 2004. Dm-myb mutant lethality in Drosophila is dependent upon mip130: Positive and negative regulation of DNA replication. Genes \& Dev. 18: 1667-1680.

Beall, E.L., Lewis, P.W., Bell, M., Rocha, M., Jones, D.L., and Botchan, M.R. 2007. Discovery of tMAC: A Drosophila testis-specific meiotic arrest complex paralogous to Myb-Muv B. Genes \& Dev. 21: 904-919.

Buffin, E., Lefebvre, C., Huang, J., Gagou, M.E., and Karess, R.E. 2005. Recruitment of Mad2 to the kinetochore requires the Rod/Zw10 complex. Curr. Biol. 15: 856-861.

Cayirlioglu, P., Bonnette, P.C., Dickson, M.R., and Duronio, R.J. 2001. Drosophila E2f2 promotes the conversion from genomic DNA replication to gene amplification in ovarian follicle cells. Development 128: 5085-5098.

Ceol, C.J., Stegmeier, F., Harrison, M.M., and Horvitz, H.R. 2006. Identification and classification of genes that act antagonistically to let-60 Ras signaling in Caenorhabditis elegans vulval development. Genetics 173: 709-726.

Classon, M. and Harlow, E. 2002. The retinoblastoma tumour suppressor in development and cancer. Nat. Rev. Cancer 2: 910-917.

Davidson, C., Ray, E., and Lipsick, J. 2004. Evolution of Myb proteins. In $M y b$ transcription factors: Their role in growth, differentiation and disease (ed. J. Frampton), pp. 1-33. Kluwer Academic Publishers, Boston. 
Davidson, C., Tirouvanziam, R., Herzenberg, L., and Lipsick, J. 2005. Functional evolution of the vertebrate Myb gene family: B-Myb, but neither A-Myb nor c-Myb, complements Drosophila Myb in hemocytes. Genetics 169: 215-229.

Dimova, D.K. and Dyson, N.J. 2005. The E2F transcriptional network: Old acquaintances with new faces. Oncogene 24: 2810-2826.

Dimova, D.K., Stevaux, O., Frolov, M.V., and Dyson, N.J. 2003. Cell cycle-dependent and cell cycle-independent control of transcription by the Drosophila E2F/RB pathway. Genes \& Dev. 17: 2308-2320.

Duronio, R.J., O'Farrell, P.H., Xie, J.E., Brook, A., and Dyson, N. 1995. The transcription factor E2F is required for $S$ phase during Drosophila embryogenesis. Genes \& Dev. 9: 1445-1455.

Eissenberg, J.C. and Wallrath, L.L. 2003. Heterochromatin, position effects, and the genetic dissection of chromatin. Prog. Nucleic Acid Res. Mol. Biol. 74: 275-299.

Ferguson, E.L. and Horvitz, H.R. 1989. The multivulva phenotype of certain Caenorhabditis elegans mutants results from defects in two functionally redundant pathways. Genetics 123: 109-121.

Frolov, M.V., Huen, D.S., Stevaux, O., Dimova, D., BalczarekStrang, K., Elsdon, M., and Dyson, N.J. 2001. Functional antagonism between E2F family members. Genes \& Dev. 15: 2146-2160.

Fung, S.M., Ramsay, G., and Katzen, A.L. 2002. Mutations in Drosophila myb lead to centrosome amplification and genomic instability. Development 129: 347-359.

Georlette, D., Ahn, S., MacAlpine, D.M., Cheung, E., Lewis, P.W., Beall, E.L., Bell, S.P., Speed, T., Manak, J.R., and Botchan, M.R. 2007. Genomic profiling and expression studies reveal both positive and negative activities for the Drosophila Myb MuvB/dREAM complex in proliferating cells. Genes \& Dev. 21: 2880-2896.

Glover, D.M. 2005. Polo kinase and progression through $M$ phase in Drosophila: A perspective from the spindle poles. Oncogene 24: 230-237.

Golic, K.G. 1991. Site-specific recombination between homologous chromosomes in Drosophila. Science 252: 958-961.

Gonzalo, S., Garcia-Cao, M., Fraga, M.F., Schotta, G., Peters, A.H., Cotter, S.E., Eguia, R., Dean, D.C., Esteller, M., Jenuwein, T., et al. 2005. Role of the RB1 family in stabilizing histone methylation at constitutive heterochromatin. Nat. Cell Biol. 7: 420-428.

Gottschling, D.E. 2004. Summary: Epigenetics-From phenomenon to field. Cold Spring Harb. Symp. Quant. Biol. 69: 507519.

Greenspan, R.J. 1997. Fly pushing: The theory and practice of Drosophila genetics. Cold Spring Harbor Laboratory Press, Cold Spring Harbor, NY.

Harrison, M.M., Ceol, C.J., Lu, X., and Horvitz, H.R. 2006. Some C. elegans class B synthetic multivulva proteins encode a conserved LIN-35 Rb-containing complex distinct from a NuRD-like complex. Proc. Natl. Acad. Sci. 103: 16782-16787.

Hernando, E., Nahle, Z., Juan, G., Diaz-Rodriguez, E., Alaminos, M., Hemann, M., Michel, L., Mittal, V., Gerald, W., Benezra, R., et al. 2004. $\mathrm{Rb}$ inactivation promotes genomic instability by uncoupling cell cycle progression from mitotic control. Nature 430: 797-802.

Ito, M., Araki, S., Matsunaga, S., Itoh, T., Nishihama, R., Machida, Y., Doonan, J.H., and Watanabe, A. 2001. G2/Mphase-specific transcription during the plant cell cycle is mediated by c-Myb-like transcription factors. Plant Cell 13: 1891-1905.

Karess, R. 2005. Rod-Zw 10-Zwilch: A key player in the spindle checkpoint. Trends Cell Biol. 15: 386-392.
Katzen, A.L., Kornberg, T.B., and Bishop, J.M. 1985. Isolation of the proto-oncogene c-myb from D. melanogaster. Cell 41: 449-456.

Katzen, A.L., Jackson, J., Harmon, B.P., Fung, S.M., Ramsay, G., and Bishop, J.M. 1998. Drosophila myb is required for the G2/M transition and maintenance of diploidy. Genes \& Dev. 12: 831-843.

Knoepfler, P.S., Zhang, X.Y., Cheng, P.F., Gafken, P.R., McMahon, S.B., and Eisenman, R.N. 2006. Myc influences global chromatin structure. $E M B O$ J. 25: 2723-2734.

Kops, G.J., Weaver, B.A., and Cleveland, D.W. 2005. On the road to cancer: Aneuploidy and the mitotic checkpoint. Nat. Rev. Cancer 5: 773-785.

Korenjak, M., Taylor-Harding, B., Binne, U.K., Satterlee, J.S., Stevaux, O., Aasland, R., White-Cooper, H., Dyson, N., and Brehm, A. 2004. Native E2F/RBF complexes contain Mybinteracting proteins and repress transcription of developmentally controlled E2F target genes. Cell 119: 181-193.

Kotake, Y., Cao, R., Viatour, P., Sage, J., Zhang, Y., and Xiong, Y. 2007. pRB family proteins are required for H3K27 trimethylation and Polycomb repression complexes binding to and silencing p16INK $4 \alpha$ tumor suppressor gene. Genes \& Dev. 21: 49-54.

Lai, J.-S. and Herr, W. 1992. Ethidium bromide provides a simple tool for identifying genuine DNA-independent protein associations. Proc. Natl. Acad. Sci. 89: 6958-6962.

Lewis, E.B. 1978. A gene complex controlling segmentation in Drosophila. Nature 276: 565-570.

Lewis, P.W., Beall, E.L., Fleischer, T.C., Georlette, D., Link, A.J., and Botchan, M.R. 2004. Identification of a Drosophila MybE2F2/RBF transcriptional repressor complex. Genes \& Dev. 18: $2929-2940$.

Lipsick, J.S. 2004. synMuv verite-Myb comes into focus. Genes \& Dev. 18: 2837-2844.

Lipsick, J.S. and Wang, D.M. 1999. Transformation by v-Myb. Oncogene 18: 3047-3055.

Litovchick, L., Sadasivam, S., Florens, L., Zhu, X., Swanson, S.K., Velmurugan, S., Chen, R., Washburn, M.P., Liu, X.S., and Decaprio, J.A. 2007. Evolutionarily conserved multisubunit RBL2/p130 and E2F4 protein complex represses human cell cycle-dependent genes in quiescence. Mol. Cell 26: 539-551.

Lund, A.H. and van Lohuizen, M. 2004. Epigenetics and cancer. Genes \& Dev. 18: 2315-2335.

Manak, J.R., Mitiku, N., and Lipsick, J.S. 2002. Mutation of the Drosophila homologue of the Myb protooncogene causes genomic instability. Proc. Natl. Acad. Sci. 99: 7438-7443.

Manak, J.R., Wen, H., Tran, V., Andrejka, L., and Lipsick, J.S. 2007. Loss of Drosophila Myb interrupts the progression of chromosome condensation. Nat. Cell Biol. 9: 581-587.

Michel, L.S., Liberal, V., Chatterjee, A., Kirchwegger, R., Pasche, B., Gerald, W., Dobles, M., Sorger, P.K., Murty, V.V., and Benezra, R. 2001. MAD2 haplo-insufficiency causes premature anaphase and chromosome instability in mammalian cells. Nature 409: 355-359.

Morin, X., Daneman, R., Zavortink, M., and Chia, W. 2001. A protein trap strategy to detect GFP-tagged proteins expressed from their endogenous loci in Drosophila. Proc. Natl. Acad. Sci. 98: 15050-15055.

Moutinho-Santos, T., Sampaio, P., Amorim, I., Costa, M., and Sunkel, C.E. 1999. In vivo localisation of the mitotic POLO kinase shows a highly dynamic association with the mitotic apparatus during early embryogenesis in Drosophila. Biol. Cell. 91: 585-596.

Mucenski, M.L., McLain, K., Kier, A.B., Swerdlow, S.H., Schreiner, C.M., Miller, T.A., Pietryga, D.W., Scott Jr., W.J., and Potter, S.S. 1991. A functional c-myb gene is required for 
Wen et al.

normal murine fetal hepatic hematopoiesis. Cell 65: 677-689.

Muller, H.J. 1930. Types of visible variations induced by X-rays in Drosophila. J. Genet. 12: 299-334.

Musacchio, A. and Salmon, E.D. 2007. The spindle-assembly checkpoint in space and time. Nat. Rev. Mol. Cell Biol. 8: 379-393.

Neufeld, T.P., de la Cruz, A.F., Johnston, L.A., and Edgar, B.A. 1998. Coordination of growth and cell division in the Drosophila wing. Cell 93: 1183-1193.

Nielsen, S.J., Schneider, R., Bauer, U.M., Bannister, A.J., Morrison, A., O'Carroll, D., Firestein, R., Cleary, M., Jenuwein, T., Herrera, R.E., et al. 2001. Rb targets histone $\mathrm{H} 3$ methylation and HP1 to promoters. Nature 412: 561-565.

O'Geen, H., Nicolet, C.M., Blahnik, K., Green, R., and Farnham, P.J. 2006. Comparison of sample preparation methods for ChIP-chip assays. Biotechniques 41: 577-580.

Okada, M., Akimaru, H., Hou, D.X., Takahashi, T., and Ishii, S. 2002. Myb controls $G(2) / M$ progression by inducing cyclin $B$ expression in the Drosophila eye imaginal disc. EMBO J. 21: 675-684.

Paik, S., Shak, S., Tang, G., Kim, C., Baker, J., Cronin, M., Baehner, F.L., Walker, M.G., Watson, D., Park, T., et al. 2004. A multigene assay to predict recurrence of tamoxifen-treated, node-negative breast cancer. N. Engl. J. Med. 351: 2817-2826.

Pandey, R., Heidmann, S., and Lehner, C.F. 2005. Epithelial reorganization and dynamics of progression through mitosis in Drosophila separase complex mutants. J. Cell Sci. 118: 733 742.

Pilkinton, M., Sandoval, R., and Colamonici, O.R. 2007. Mammalian Mip/LIN-9 interacts with either the p107, p130/E2F4 repressor complex or B-Myb in a cell cycle-phase-dependent context distinct from the Drosophila dREAM complex. Oncogene 26: 7535-7543.

Ren, B., Cam, H., Takahashi, Y., Volkert, T., Terragni, J., Young, R.A., and Dynlacht, B.D. 2002. E2F integrates cell cycle progression with DNA repair, replication, and $\mathrm{G}(2) / \mathrm{M}$ checkpoints. Genes \& Dev. 16: 245-256.

Rudolph, T., Yonezawa, M., Lein, S., Heidrich, K., Kubicek, S., Schafer, C., Phalke, S., Walther, M., Schmidt, A., Jenuwein, T., et al. 2007. Heterochromatin formation in Drosophila is initiated through active removal of H3K4 methylation by the LSD1 homolog SU(VAR)3-3. Mol. Cell 26: 103-115.

Schmit, F., Korenjak, M., Mannefeld, M., Schmitt, K., Franke, C., von Eyss, B., Gagrica, S., Hanel, F., Brehm, A., and Gaubatz, S. 2007. LINC, a human complex that is related to pRB-containing complexes in invertebrates regulates the expression of G2/M genes. Cell Cycle 6: 1903-1913.

Schotta, G., Ebert, A., Dorn, R., and Reuter, G. 2003. Positioneffect variegation and the genetic dissection of chromatin regulation in Drosophila. Semin. Cell Dev. Biol. 14: 67-75.

Schuettengruber, B., Chourrout, D., Vervoort, M., Leblanc, B., and Cavalli, G. 2007. Genome regulation by polycomb and trithorax proteins. Cell 128: 735-745.

Schulze, S.R. and Wallrath, L.L. 2007. Gene regulation by chromatin structure: Paradigms established in Drosophila melanogaster. Annu. Rev. Entomol. 52: 171-192.

Shepard, J.L., Amatruda, J.F., Stern, H.M., Subramanian, A., Finkelstein, D., Ziai, J., Finley, K.R., Pfaff, K.L., Hersey, C., Zhou, Y., et al. 2005. A zebrafish bmyb mutation causes genome instability and increased cancer susceptibility. Proc. Natl. Acad. Sci. 102: 13194-13199.

Sotillo, R., Hernando, E., Diaz-Rodriguez, E., Teruya-Feldstein, J., Cordon-Cardo, C., Lowe, S.W., and Benezra, R. 2007. Mad2 overexpression promotes aneuploidy and tumorigenesis in mice. Cancer Cell 11: 9-23.

Stober-Grasser, U., Brydolf, B., Bin, X., Grasser, F., Firtel, R.A., and Lipsick, J.S. 1992. The Myb DNA-binding domain is highly conserved in Dictyostelium discoideum. Oncogene 7: 589-596.

Takai, N., Hamanaka, R., Yoshimatsu, J., and Miyakawa, I. 2005. Polo-like kinases (Plks) and cancer. Oncogene 24: 287291.

Tanaka, Y., Patestos, N.P., Maekawa, T., and Ishii, S. 1999. $\mathrm{B}-\mathrm{myb}$ is required for inner cell mass formation at an early stage of development. J. Biol. Chem. 274: 28067-28070.

Toscani, A., Mettus, R.V., Coupland, R., Simpkins, H., Litvin, J., Orth, J., Hatton, K.S., and Reddy, E.P. 1997. Arrest of spermatogenesis and defective breast development in mice lacking A-myb. Nature 386: 713-717.

Vandel, L., Nicolas, E., Vaute, O., Ferreira, R., Ait-Si-Ali, S., and Trouche, D. 2001. Transcriptional repression by the retinoblastoma protein through the recruitment of a histone methyltransferase. Mol. Cell. Biol. 21: 6484-6494.

Wulbeck, C. and Helfrich-Forster, C. 2007. RNA in situ hybridizations on Drosophila whole mounts. Methods Mol. Biol. 362: 495-511.

Zhu, W., Giangrande, P.H., and Nevins, J.R. 2004. E2Fs link the control of G1/S and G2/M transcription. EMBO J. 23: 46154626. 


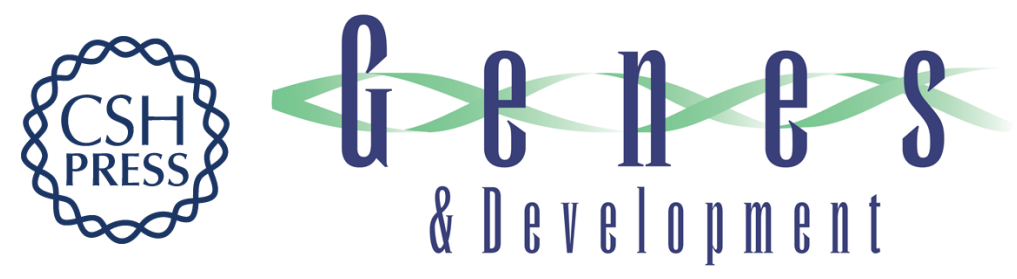

\section{Epigenetic regulation of gene expression by Drosophila Myb and E2F2 -RBF via the Myb-MuvB/dREAM complex}

Hong Wen, Laura Andrejka, Jonathan Ashton, et al.

Genes Dev. 2008, 22:

Access the most recent version at doi:10.1101/gad.1626308

\section{Supplemental http://genesdev.cshlp.org/content/suppl/2008/03/03/22.5.601.DC1 Material}

References This article cites 69 articles, 30 of which can be accessed free at: http://genesdev.cshlp.org/content/22/5/601.full.html\#ref-list-1

\section{License}

Email Alerting

Receive free email alerts when new articles cite this article - sign up in the box at the top Service

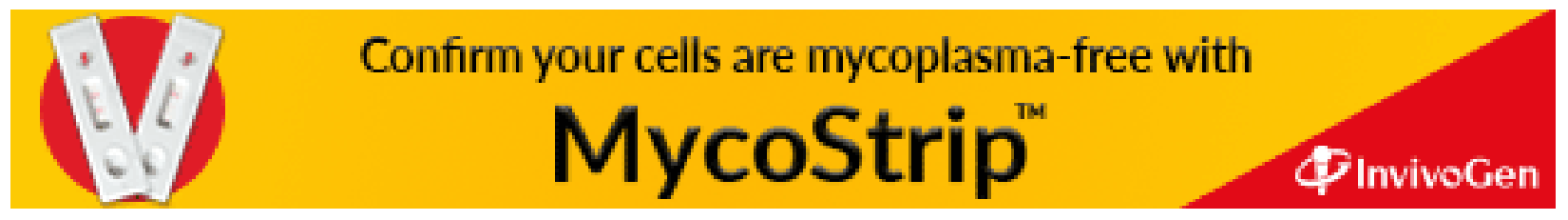

